\title{
TelePresence in Rural Medical Education: A Mixed Methods Evaluation
}

\author{
Katherine Gray, ${ }^{1}$ Kristian Krogh, ${ }^{2,3,4}$ David Newsome, ${ }^{1}$ Victoria Smith, ${ }^{1}$ \\ Donald Lancaster, ${ }^{1}$ and Debra Nestel ${ }^{1,4,5}$ \\ ${ }^{1}$ Gippsland Medical School, Monash University, Churchill, VIC, Australia \\ ${ }^{2}$ Centre for Medical Education, Aarhus University, Aarhus, Denmark \\ ${ }^{3}$ SkejSim Medical Simulation \& Skills Training, Aarhus, Denmark \\ ${ }^{4}$ School of Rural Health, Monash University, VIC, Australia \\ ${ }^{5}$ Health Professions Education and Educational Research (HealthPEER), Faculty of Medicine, Nursing and Health Sciences, \\ Monash University, VIC, Australia
}

Correspondence should be addressed to Kristian Krogh; kk@medu.au.dk

Received 25 October 2013; Accepted 28 December 2013; Published 10 February 2014

Academic Editor: Saeed Farooq

Copyright (C) 2014 Katherine Gray et al. This is an open access article distributed under the Creative Commons Attribution License, which permits unrestricted use, distribution, and reproduction in any medium, provided the original work is properly cited.

\begin{abstract}
In response to rural health workforce shortages, universities and training providers offer rural and remote clinical placements. This has led to development of educational methods to counter the barriers of distance. In this emerging field, recent improvements in technology have provided solutions including the use of sophisticated videoconferencing systems such as the Cisco TelePresence model CTS-500. This paper evaluates the use of TelePresence in diverse medical education activities using a mixed methods design-questionnaires $(n=60)$, individual interviews $(n=33)$, and observed practice of activities $(n=22)$. TelePresence was found to be beneficial to learning and teaching and superior to other systems participants had used. In particular, the audiovisual quality, resulting intimacy, convenience, and ease of use facilitated teaching and learning, while the fixed camera and poorly arranged physical environment were found to be limitations. The system is best suited for small group activities. Clinical skills-based activities are viable. It is recommended that technical support be available during setup and use and a picture-in-picture mode be included and improved integration of office suite software to provide a joint workspace for display of presentations, images, editing or annotation of documents, and file sharing.
\end{abstract}

\section{Introduction}

There is a shortage of doctors in rural Australia further compounded by a lack of resources in this setting [1]. Medical education programs have seen an increased focus on rural and remote medicine and this has manifested in new rural based medical schools [2]. Funded by the Federal and State Governments to address to National Rural Health Workforce Strategy, Monash University opened the Gippsland Medical School (GMS) in Churchill, Victoria, in 2008 [3]. As part of the Faculty of Medicine, Nursing and Health Sciences, GMS provides a four-year graduate entry medical degree. The current cohort has ninety students, with more than twenty clinical sites over 22,000 square kilometres in eastern Victoria [3]. With this vast area, it is a significant challenge to provide appropriate teaching and learning facilities for staff and students. However, with the advent of new technologies and the improvement of internet services, the barrier of distance can be overcome to provide educational opportunities via teleconferencing systems [4]. Cisco provided Monash University with two TelePresence (TP) units with the goal of exploring their application in a range of educational activities. The units were installed at two sites in the region.

Historical rurally based institutions in particular have a need for distance education and have a high demand for new educational techniques to counter the impacts of distance. Online systems are currently in use in a wide range of distance education settings where teacher and student are separated by both time and space, for example, via email, discussion 
boards, or recordings $[4,5]$. This is referred to as synchronous distance education [5]. The important factor here is that two-way dialogue can be achieved immediately and student knowledge and behaviour evaluated [6]. Although this may not be perceived as the ideal educational scenario, at the very least it provides an avenue for educational access that would not otherwise be possible [5].

Studies have shown the effectiveness and efficiency of learning and teaching using teleconferencing $[7,8]$, reported as being an appropriate alternative [9] or in some cases as equivalent to "in person" teaching $[10,11]$. It has also been shown that participant attendance can be increased when using these teleconference systems, because of increased access [12]. Further, the time restraints imposed by travel and increased costs of accommodation and commuting can be eliminated allowing more time for education and less time for staff out of clinical practice [6]. Conversely these methods of distance education also allow those who prefer to live and practice rurally the freedom to do so, while still having access to the same continuing educational opportunities as their metropolitan counterparts [5].

Teleconferencing can be defined as real time interaction in which participants are at one or more locations communicating via an interactive audio-video communication system [13]. This allows for interaction between the sites without having to meet physically and can be used for teaching, consultation, diagnosis, and treatment. The later through telementoring during surgical procedures [14]. This enables constructivist approaches to learning where knowledge and meaning are constructed through direct dialogue and problem solving [15].

There are many different approaches to the delivery of distance education. Examples include combinations of media such as print, videoconferencing, audio and video recordings, interactive applications, email, video animations, interactive online discussion forums, CDs, video streaming, and teleconferencing $[4,16,17]$. The advent of faster and more accessible internet, as well as improvements and reduction in costs of smartphones and tablets, has resulted in a rapidly changing landscape of educational methods. Currently, teleconferencing appears to be the most widely used and researched method of delivery in medical education. In a US based study on continuing medical education using teleconferencing, Ricci et al. reported that $79 \%$ of participants found the program at least as effective as in person teaching and $18 \%$ did not have to travel as a result of the telemedicine program [18]. The effectiveness of teleconferencing programs has also been shown as having at least equivalence to in person teaching in two other studies $[10,11]$ and of having value in four other studies [14, 19-21]. The most reported benifits are reduced travel time and access to wider audiences with reduced resource [22].

For students and clinicians studying and working in rural and remote areas there are limited avenues for education. In a country such as Australia, where clinical sites can be hundreds of kilometres from the nearest major city, attending classes geographically distant to the clinical site is challenging. Teleconferencing can overcome this problem providing effective education that would not have otherwise been possible [10]. However, there are challenges too such as the need for specific infrastructure and the associated costs. An effective teleconferencing system requires adequate equipment including video and audio recording and projection, reliable high bandwidth internet connection, and appropriate software that represent a significant outlay of time and money. Teleconferencing also has limitations as to what can be done using such a system when compared to a traditional classroom.

We developed the following research questions to evaluate the use of the teleconferencing system TP in medical education.

(1) What elements of TP facilitate learning and teaching in selected medical education activities?

(2) What elements of TP hinder learning and teaching in selected medical education activities?

\section{Materials and Methods}

The teleconferencing system used for this study was the Cisco TelePresence unit model CTS-500, a high definition (1080 p) $37^{\prime \prime}$ display. At the remote unit a similar Cisco TP CTS-500 was connected through a dedicated broadband connection. The broadband connection had a 2 Mbps uplink and $10 \mathrm{Mbps}$ downlink. For the voice, video, and AUX port (slide sharing) traffic from the CTS-500 is approximately $1.5 \mathrm{Mbps}$ of sustained traffic for each connected unit $[23,24]$. Figure 1 illustrates the setup of the TP unit [24].

Diverse educational activities were used to test the breadth and depth of applications of TP supported learning across participants, content, methods, and domains (knowledge, attitudes, and skills).

The research questions were addressed using mixed methods. Purposive sampling was used to identify participants for the educational activities. There were three data collection methods-questionnaires, interviews, and observations.

Participants were invited to complete a questionnaire exploring their experiences of teaching and/or learning with TP. The questionnaire included a request for demographic information and a six-point ordinal scale for participants to rate various aspects of TP (Appendix 1 in Supplementary Material available online at http://dx.doi.org/ 10.1155/2014/823639). Scores exceeding 4.5 were established as our aspirational standard. The questionnaire allowed comparisons across educational activities and participants. Numerical data was entered into SPSS17.0 and descriptive statistics computed.

Individual interviews were conducted with participants after the TP activity. A research team member used a topic guide to ensure similar questions were asked in each interview (Appendix 2). Interviews were audio recorded and transcribed. After deidentification, each transcript was analysed thematically by two researchers.

At each TP site, one researcher observed the TP supported learning activity and used a template to record observations (Appendix 3). Researchers commented on a range of aspects of the communication via TP including the length 


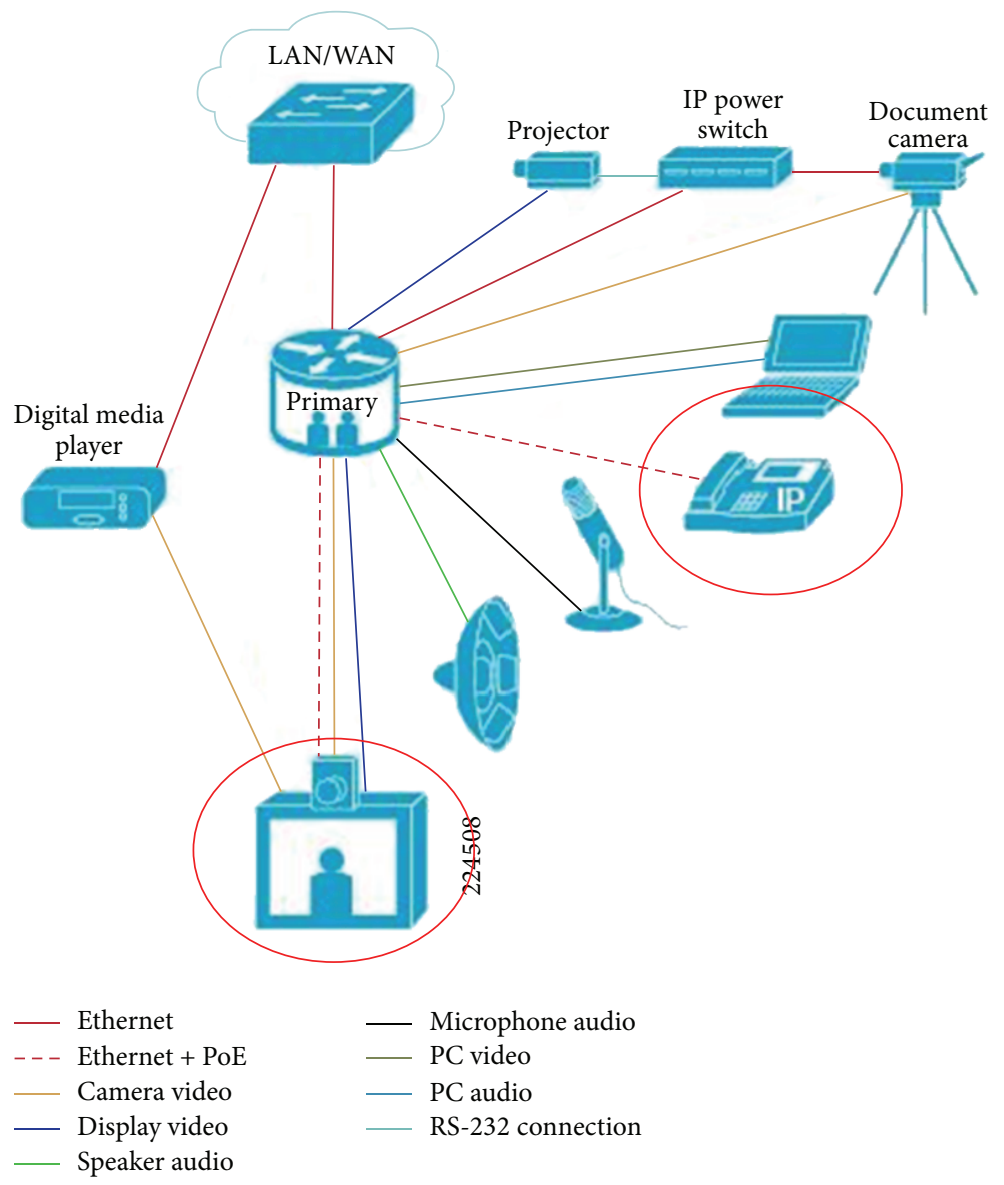

Figure 1: Schematic representation of the TelePresence system as it appeared on both ends. The actual interface for the users (on either end) are the IP phone and the display/camera circled above [24].

of sessions, input from each site, and level of interaction of participants. Free text was analysed thematically.

\section{Results and Discussion}

3.1. Educational Activities. Eighteen educational activities were undertaken and summarised in Table 1. Knowledge, attitude, and skills-based activities were conducted with diverse participants. Sessions lasted between five and 40 minutes and involved from one to four people at the teaching site and/or learning sites. The learning activities took place between April 2011 and March 2012.

3.2. Questionnaire. Fifty-nine participants were involved in the educational activities and all completed questionnaires. Participants' ages ranged from 20 to 56 years of age (mean 33 years); 35 were female $(58.3 \%)$ and 25 were male $(41.7 \%)$. The participants' roles were as simulated patients $(n=11 ; 18.3 \%)$, simulated patient trainers $(n=2 ; 3.3 \%)$, medical students $(n=27 ; 45 \%)$, international medical graduate $(n=7 ; 11.7 \%)$, postgraduate student $(n=1 ; 1.7 \%)$, postgraduate supervisor $(n=1 ; 1.7 \%)$, clinical skills teachers $(n=9 ; 15 \%)$, and anatomy/physiology teachers $(n=2 ; 3.3 \%)$.
Table 2 sets out participants' satisfaction with various elements of TP. They were most satisfied with the visual quality of TP (mean 5.46, SD 0.73) and least satisfied with the physical space around the TP unit (4.58, SD 1.12). Participant's ratings of the value of TP supported learning (4.86, SD 1.56) and teaching (4.53, SD 1.87) and exceeded the aspirational standard of 4.5 .

3.3. Interviews. Thirty-three interviews were conducted with participants and ranged from five to 15 minutes totalling almost four hours of audio recordings. All interviews were conducted immediately after the educational sessions by one of the authors. Interviews were reported as cooperative and constructive with participants willing to share their views openly and frankly. The themes were learning and teaching, increasing access to learning opportunities, educational barriers, intimacy, audio quality, and video system (including camera placement). Selected quotes are categorized according to themes in Table 3.

3.4. Learning and Teaching. Participants reported positives and negatives in relation to learning and teaching. All learning activities conducted were well received by the 
TABLE 1: Learning and teaching activities using TelePresence.

\begin{tabular}{|c|c|c|c|}
\hline Focus & $\begin{array}{c}\text { Number of } \\
\text { sessions }\end{array}$ & Description & Participants \\
\hline $\begin{array}{l}\text { Training simulated } \\
\text { patients (SPs) }\end{array}$ & 2 & $\begin{array}{l}\text { Training for SP role performance and feedback enabling } \\
\text { capacity building in SP methodology across geographical } \\
\text { regions via TelePresence }\end{array}$ & SPs and SP trainer \\
\hline $\begin{array}{l}\text { SP methodology with } \\
\text { students or international } \\
\text { medical graduates (IMGs) }\end{array}$ & 7 & $\begin{array}{l}\text { SP facilitated teaching of patient assessments skills } \\
\text { including empathic and cultural awareness testing the } \\
\text { finer grained elements of communication and access via } \\
\text { TelePresence }\end{array}$ & $\begin{array}{l}\text { SPs and medical students } \\
\text { IMGs }\end{array}$ \\
\hline $\begin{array}{l}\text { Postgraduate student } \\
\text { supervision }\end{array}$ & 1 & $\begin{array}{l}\text { Supervision of post-graduate student with specialized } \\
\text { expertise located in one area but dissemination facilitated } \\
\text { by TelePresence; assess formal academic presentation } \\
\text { skills of student }\end{array}$ & $\begin{array}{l}\text { Postgraduate supervisor } \\
\text { and postgraduate student }\end{array}$ \\
\hline Clinical skills teaching & 2 & $\begin{array}{l}\text { Opportunity for high level skills training via TelePresence } \\
\text { including detailed elements of physical examination } \\
\text { (could incorporate suturing in simulation) }\end{array}$ & $\begin{array}{l}\text { Clinical skills teachers and } \\
\text { medical students }\end{array}$ \\
\hline Peer tutoring & 3 & $\begin{array}{l}\text { Explore student led educational methods across distances } \\
\text { via TelePresence in topic of choice; includes horizontal } \\
\text { (seeking equivalence in experience) and vertical (seeking } \\
\text { near competence sharing of experience) peer tutoring }\end{array}$ & Medical students \\
\hline $\begin{array}{l}\text { Anatomy/physiology } \\
\text { master classes }\end{array}$ & 3 & $\begin{array}{l}\text { High level revision and extension of anatomy and/or } \\
\text { physiology in the context of clinical experience }\end{array}$ & $\begin{array}{l}\text { Anatomy/physiology tutors } \\
\text { and medical students }\end{array}$ \\
\hline
\end{tabular}

TABLE 2: Participants' ratings of satisfaction and value with aspects of the TelePresence from "not at all satisfied" (1) to "completely satisfied" (6) or "not at all valuable" (1) to "completely valuable" (6) $(n=60)$.

(a)

\begin{tabular}{lcc}
\hline Satisfaction & Mean & SD \\
\hline Ease of use of the technology & 5.12 & 0.83 \\
Visual quality & 5.46 & 0.73 \\
Audio quality & 4.73 & 1.31 \\
Physical space & 4.58 & 1.21 \\
\hline
\end{tabular}

(b)

\begin{tabular}{lcc}
\hline Value & Mean & SD \\
\hline Learning & 4.86 & 1.56 \\
Teaching & 4.53 & 1.87 \\
\hline
\end{tabular}

participants. Additionally, participants thought that TP had potential for further applications. There was consensus that TP was valuable for one to one learning or small group learning. While many of the participants believed that the TP unit would be a valuable teaching tool, some participants were hesitant about replacing in person teaching with TP. However, most participants thought TP would provide an appropriate alternative.

3.5. Increasing Access to Learning Opportunities. Many participants believed that TP could increase access to learning opportunities that may not be otherwise available such as access to simulated patients. Most participants appreciated the ability of TP to reduce travel time and the associated costs. Teachers and students both appreciated the reduction in the time that they needed to spend travelling and appreciated the extra time that this freed up in their busy schedules.

3.6. Educational Barriers. Several issues were raised as barriers to education. These included the fixed camera angle, not being able to share images such as an X-ray or ECG, and not being able to draw and interact with PowerPoint presentations. Although the system does allow for this, it required functionality our TP unit did not have. To overcome these issues students and teachers had to improvise. Several activities tested the system's capability to present information as well as the video display. This included slideshow presentations to deliver tutorials, interpretation of medical test results, and using a drawing function to annotate diagrams. While the option to be able to do this added value, the main criticism came from the size of the displayed image and the ease of annotation.

3.7. Intimacy. Most participants thought that TP created a feeling of sharing the same room with the person at the distant site and this created a feeling of intimacy.

3.8. Audio Quality. There were mixed responses in relation to audio quality. Although most participants were very satisfied, there were challenges in a small number of sessions. Minor audio feedback and distortion were reported in up to onethird of the sessions. In some sessions, participants struggled with the low volume so they had to concentrate intently on listening.

3.9. Video System. Participants were very impressed by the quality of the video in the TP unit. The visual quality made facial expressions easy to read and understand more clearly 


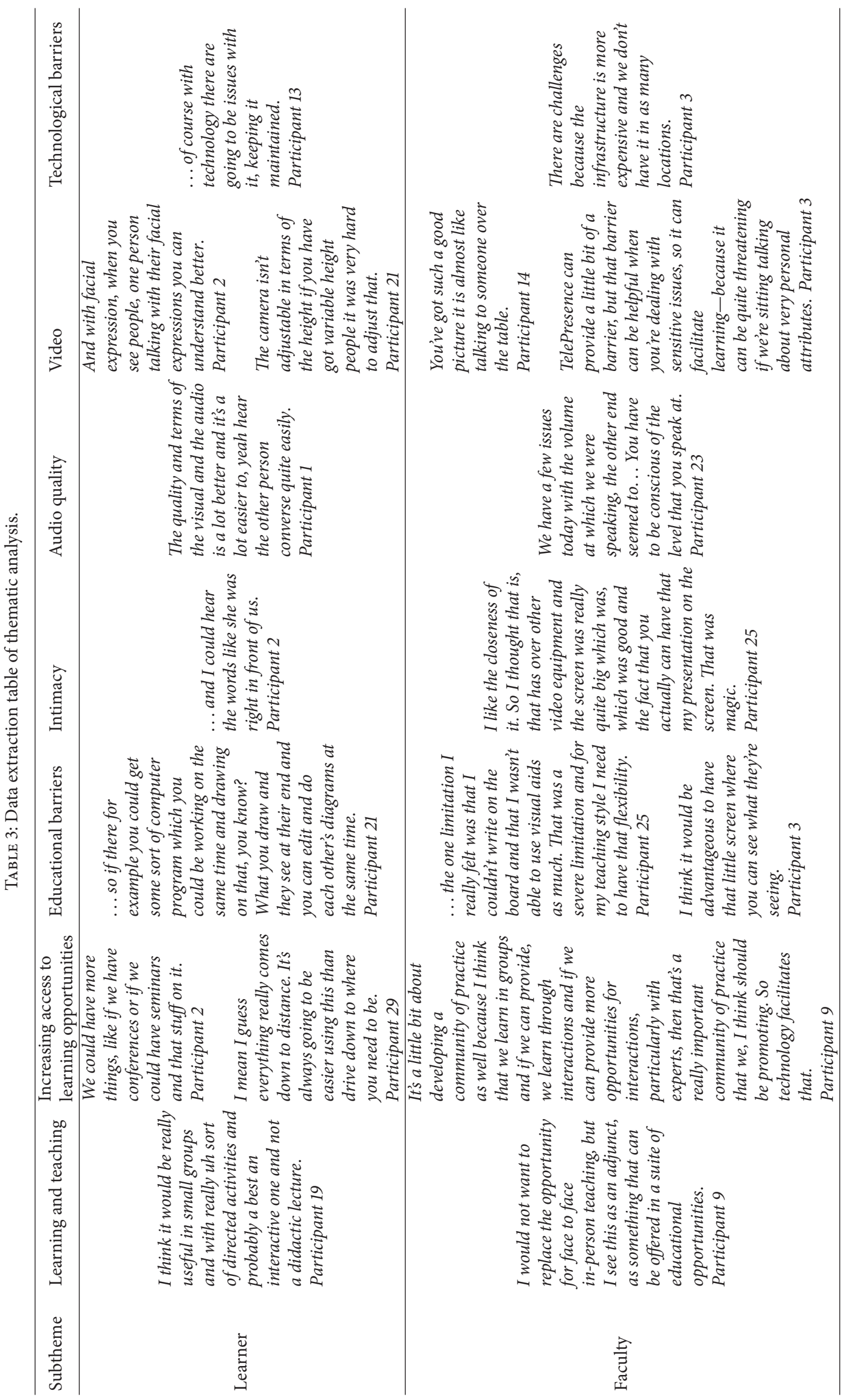


what participants at the distant site were saying. This clarity aided understanding in the few sessions in which audio quality was compromised. It was reported that the quality of the video created a feeling that participants were together in the same room.

Some participants thought the opportunity for a "picturein-picture" mode, where a small screen vision of the individual participants can be superimposed within the main visual display, would significantly improve communication. When participants could not see themselves they were unsure of their position within the screen and this affected the way they interacted with the camera. Others reported issues with sitting too close to the camera and taking up the whole screen or not sitting in the view of the camera so the participants were off screen.

Most participants thought TP superior to other teleconferencing systems that they had used with "lag time," "system freezes," or "drop-outs" consistently cited as problematic in other systems. None of these frustrations were reported with TP.

Participants noted the fixed position of the camera, at the top of the unit, the height of the camera and/or or the angle of the view could not be adjusted to accommodate for participant numbers or the equipment needs of each activity as shown in Figure 2. Although some of the activities were sit-down discussions with approximately three participants which the camera accommodated adequately, others were active and required participants to stand up and move around the room. As the camera angle was fixed and could not be changed, the room had to be setup to accommodate the camera. Participants also noted that sometimes they appeared to be avoiding eye contact, as the camera is situated above the screen while the user looks at the display in the middle display.

Some participants reported that a remote control would be useful to adjust volume, brightness, and other minor functions to accommodate needs of the individual user.

Some participants were challenged with not being able to make direct eye contact. Additionally, they did not know who else was in the room out of camera view. This created an uneasy feeling for some participants. These barriers also created the feeling of distance between the participants. However, some participants saw the distance that was created as beneficial.

3.10. Observations. Members of the research team observed each of the research activities conducted with the TP unit and made notes that were unstructured but focused on technical aspect and user friendliness. The research team conducted twenty-two observations. The observations are categorised according to learning and teaching benefits and challenges as well as the audiovisual quality. Although general observations were very positive, the data suggests otherwise since observers were encouraged to focus on identifying challenges.

3.11. Learning and Teaching Benefits and Challenges. Eleven observers made comments on the teaching with the TP unit.

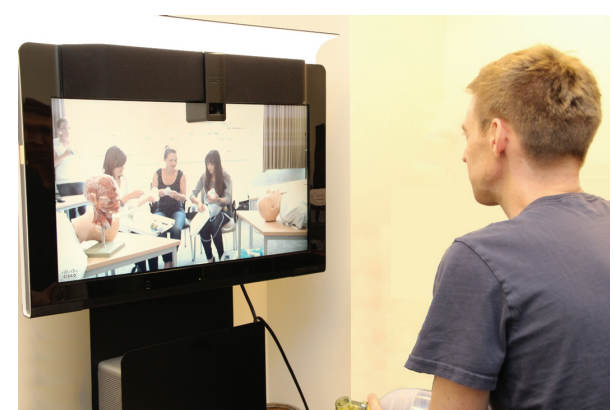

FIgUre 2: Photo of TelePresence view during a clinical skills activity from teacher perspective.

Most comments related to the benefits of teaching with the TP unit. However, for some skills-based teaching there were challenges.

3.12. Audio and Visual Quality. Most of the observers were impressed with the video quality in the TP unit. Six observers made comments about the high quality of the video although some observers noted darkness and glare on the screen. Five observers commented on the limitations of the field of view from the camera and the lack of flexibility of the camera position and the compromised quality of the audio system. Three observations were made about the background noise and its impact on the learning activity. Four observers thought the compromised audio caused communication difficulties between student and teacher and three observations were made about the inability to control the volume.

\section{Conclusions}

4.1. Benefits. Educational activities with varying levels of knowledge, attitudes, and skills and across learners with different levels of experience proved feasible with TP. Overall, TP was considered beneficial for learning and teaching reflecting previous findings using teleconferencing $[7,8]$. The aspirational standards (4.5 of 6) were exceeded. The specifications of the TP units we worked with were suited to the varied nature of the small group activities. Skills-based activities were feasible and superior to other teleconferencing facilities used by participants. The quality of the visual acuity enabled intimacy well suited to communication skills training. There was perceived value from teacher and learner, especially with respect to increasing access to educational activities as result of the reduced travel times. This being one of the most report benefits associated with teleconferencing $[10,11,14,19-21]$. For peer learning, we found that TP maintained social interactions over and above other social networks and media.

Addressing the research questions, factors that facilitate effective educational activities using TP include the audiovisual quality, resulting intimacy, convenience, and ease of use. Participants were able to setup and implement a TP supported educational activity with limited/no assistance. 
4.2. Drawbacks. There were a number of drawbacks to the use of the technology in the educational setting. The camera on the TP unit was fixed to one location in the field of view. This was constraining for both teachers and learners as they were unable to move the visual focus in accordance with the progression of the session. The size and setup of the rooms that the TP was setup in were additional constraining factors. Learners and teachers faced glare from windows and reflection on the TP screen which impacted visibility. They were also faced with restriction on their ability to move around in the room while demonstrating physical procedures. There were some difficulties with the audio system. Audio feedback and distortion were reported and were distracting for participants. Participants were unable to manipulate the TP volume and struggled with the low audio.

4.3. Improvements for the Use of TP in Medical Education. From this study, to improve the use of TP in medical education a number of recommendations can be made. Firstly it is essential that the TP unit be setup in a room that has adequate control over the lighting. Ensuring that the unit was setup in a room that had a dimmer light switch and curtains would enable participants to eliminate glare on the screen that impacts visibility.

The addition of a flexible camera to the unit would enable a greater and more rounded viewing of the teaching activity and would also improve the sharing of images and the ability to actively annotate PowerPoint presentations and diagrams. In addition to this enlarging the size of the displayed image would ease viewing and of annotation PowerPoint presentations and diagrams.

Greater participant control over the audio volume would enable a greater educational experience, easing participant's difficulties in hearing the instructor when there were issues such as background noise. Enabling flexibility of the TP speakers would also enable the participant's ability to manipulate the position of the speakers based on the setup of the room and reduce distortion and feedback experiences in the audio system.

The use of TP in this study is shown to be beneficial for teaching and learning and was overwhelmingly superior to other teleconferencing experiences used by participants. These findings are echoed in the literature with the use of teleconferencing for teaching and learning. Further research should push the boundaries of the technology of TP by increasing the distance between sites, having multiple sites participate and setups for larger groups.

\section{Ethical Approval}

Ethics approval was obtained from the Monash University Human Research Ethics Committee (MUHREC) (CF10/18212010000989).

\section{Conflict of Interests}

The authors declare that there is no conflict of interests regarding the publication of this paper.

\section{Acknowledgments}

The following colleagues and programs supported this project: (i) Associate Professor David Campbell, East Gippsland Regional Clinical School, Monash University; (ii) Mr. Kheeran Dharmawardena, Information Technology Services, Monash University; (iii) Dr. Anneke Graf, Faculty of Medicine, Nursing and Health Sciences, Monash University; (iv) Cisco for the provision of the TelePresence Units; (v) Monash-Warwick Learning and Teaching Fellowship 2011.

\section{References}

[1] Australian Government, "Report on the audit of health workforce in rural and regional Australia," in Ageing, Australian Government Department of Health and Ageing (DoHA), Ed., Commonwealth of Australia, Canberra, Australia, 2008.

[2] L. G. Peachey and K. E. McBain-Rigg, "The challenges of remote area medical education," Medical Journal of Australia, vol. 194, no. 10, pp. 495-496, 2011.

[3] Monash University, School of Rural Health, 2011, http://www .med.monash.edu.au/assets/docs/srh/intro-srh-aug2011.pdf.

[4] M. F. Carrière and D. Harvey, "Current state of distance continuing medical education in North America," The Journal of Continuing Education in the Health Professions, vol. 21, no. 3, pp. 150-157, 2001.

[5] F. B. King, B. C. Smith, and M. B. Mathews, "Health professions' education and practice: a commentary on transformation through the internet," Journal of Allied Health, vol. 35, no. 3, pp. 174-178, 2006.

[6] R. Folberg, J. V. Linberg, R. E. Verdick, and T. A. Weingeist, "Distance education for the professional: the web and beyond," Ophthalmology Clinics of North America, vol. 13, no. 2, pp. 225237, 2000.

[7] A. Jain, R. Agarwal, D. Chawla, V. Paul, and A. Deorari, “Teleeducation versus classroom training of neonatal resuscitation: a randomized trial," Journal of Perinatology, vol. 30, no. 12, pp. 773-779, 2010.

[8] K. Latifi, I. Lecaj, F. Bekteshi et al., "Cost-benefit analysis on the use of telemedicine program of Kosova for continuous medical education: a sustainable and efficient model to rebuild medical systems in developing countries," Telemedicine Journal and eHealth, vol. 17, no. 10, pp. 757-762, 2011.

[9] A. Cook, J. L. P. Salle, J. Reid et al., "Prospective evaluation of remote, interactive videoconferencing to enhance urology resident education: the genitourinary teleteaching initiative," Journal of Urology, vol. 174, no. 5, pp. 1958-1960, 2005.

[10] H. Knapp, K. Chan, H. D. Anaya, and M. B. Goetz, "Interactive internet-based clinical education: an efficient and cost-savings approach to point-of-care test training," Telemedicine and $e$ Health, vol. 17, no. 5, pp. 335-340, 2011.

[11] P. A. Schweickert, C. M. Rutledge, D. C. Cattell-Gordon et al., "Telehealth stroke education for rural elderly virginians," Telemedicine and e-Health, vol. 17, no. 10, pp. 784-788, 2011.

[12] C. Murphy-Southwick and M. McBride, "Geriatric education across 94 million acres: adapting conference programming in a rural state," Gerontology and Geriatrics Education, vol. 26, no. 4, pp. 25-36, 2006.

[13] Society of American Gastrointestinal and Endoscopice Surgeons, Guidelines for the Surgical Practice of Telemedicine, 
Practice/Clinical Guidelines, 2009, http://www.sages.org/publication/id/21.

[14] H. Sebajang, P. Trudeau, A. Dougall, S. Hegge, C. McKinley, and M. Anvari, "Telementoring: an important enabling tool for the community surgeon," Surgical Innovation, vol. 12, no. 4, pp. 327331, 2005.

[15] D. Nestel, E. Villanueva, C. Browne et al., Mobile Learning in Medical Education: Evaluation and Development of Pedagogy to Maximise Utility, Gippsland Medical School, Monash University, 2009.

[16] M. Shaw, "Proposing continuing medical education for the Pacific," Pacific Health Dialog, vol. 7, no. 2, pp. 86-87, 2000.

[17] M. P. Paixão, H. A. Miot, J. O. Filho, and C. L. Wen, "Dermatúnel: a model of interactive learning environment in dermatology," Saúde e Sociedade, vol. 18, no. 4, pp. 800-808, 2009.

[18] M. A. Ricci, M. P. Caputo, P. W. Callas, and M. Gagne, "The use of telemedicine for delivering continuing medical education in rural communities," Telemedicine Journal and e-Health, vol. 11, no. 2, pp. 124-129, 2005.

[19] A. Okrainec, O. Henao, and G. Azzie, "Telesimulation: an effective method for teaching the fundamentals of laparoscopic surgery in resource-restricted countries," Surgical Endoscopy and Other Interventional Techniques, vol. 24, no. 2, pp. 417-422, 2010.

[20] P. W. Callas, T. F. Bertsch, M. P. Caputo, B. S. Flynn, S. Doheny-Farina, and M. A. Ricci, "Medical student evaluations of lectures attended in person or from rural sites via interactive videoconferencing," Teaching and Learning in Medicine, vol. 16, no. 1, pp. 46-50, 2004.

[21] B. Himpens, "The Pentalfa project. 1: the development of distance continuing medical education via videoconferencing in the Dutch-speaking region of Belgium," Journal of Telemedicine and Telecare, vol. 9, no. 2, pp. 99-103, 2003.

[22] J. A. Loera, Y. Kuo, and R. R. Rahr, "Telehealth distance mentoring of students," Telemedicine Journal and e-Health, vol. 13, no. 1, pp. 45-50, 2007.

[23] Cisco TelePresence System 500 Assembly, First-Time Setup, and Field Replaceable Unit Guide, Cisco System, 2008.

[24] Cisco TelePresence Network Systems 2.0 Design Guide, Cisco System, 2009. 

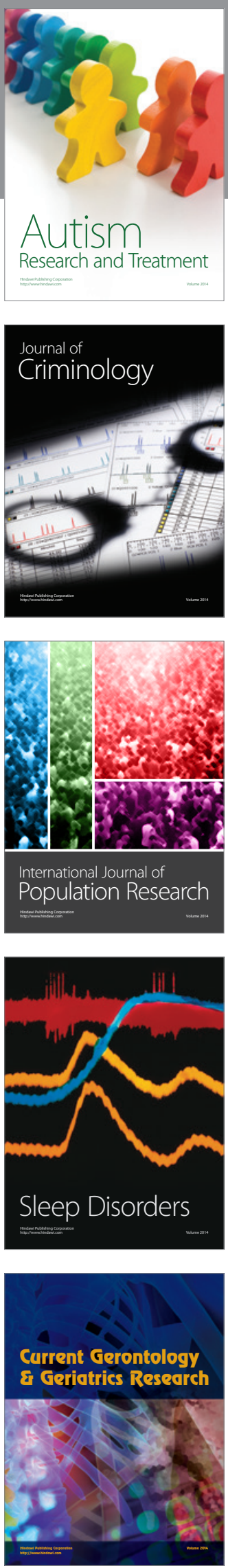
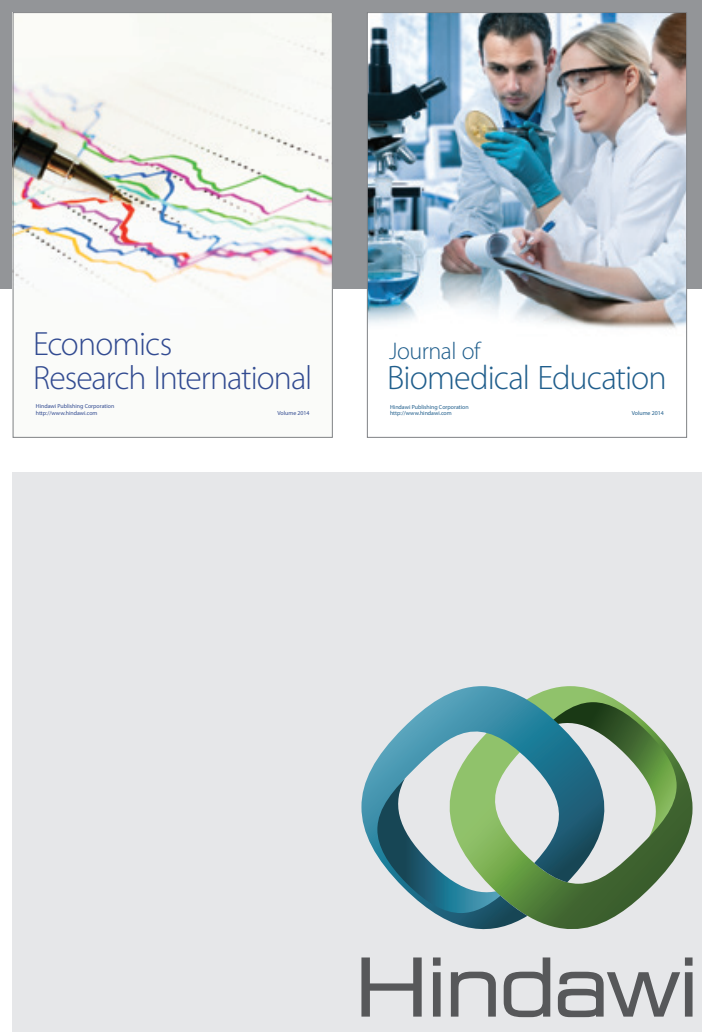

Submit your manuscripts at

http://www.hindawi.com
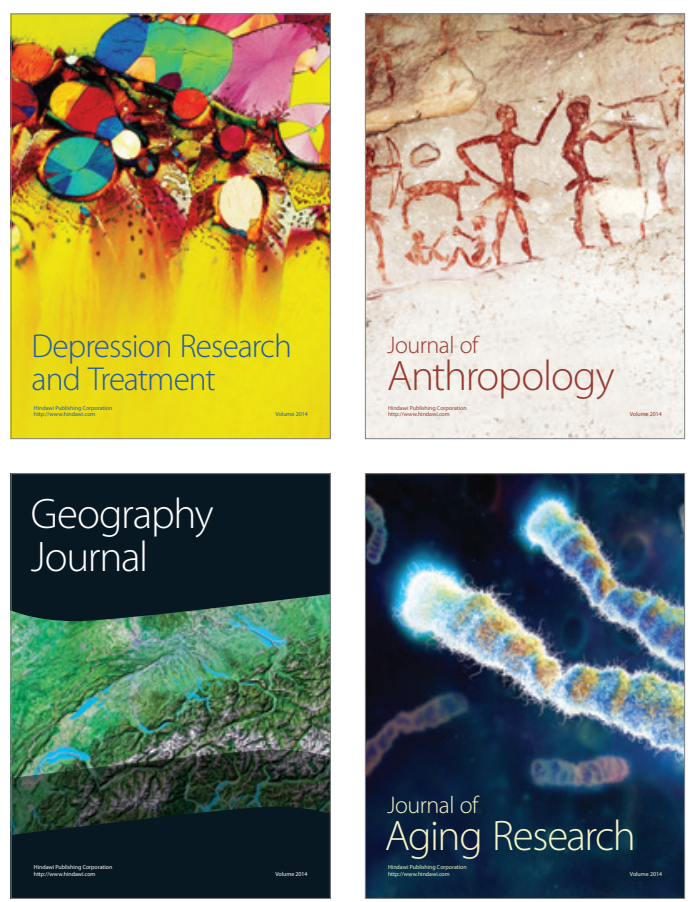
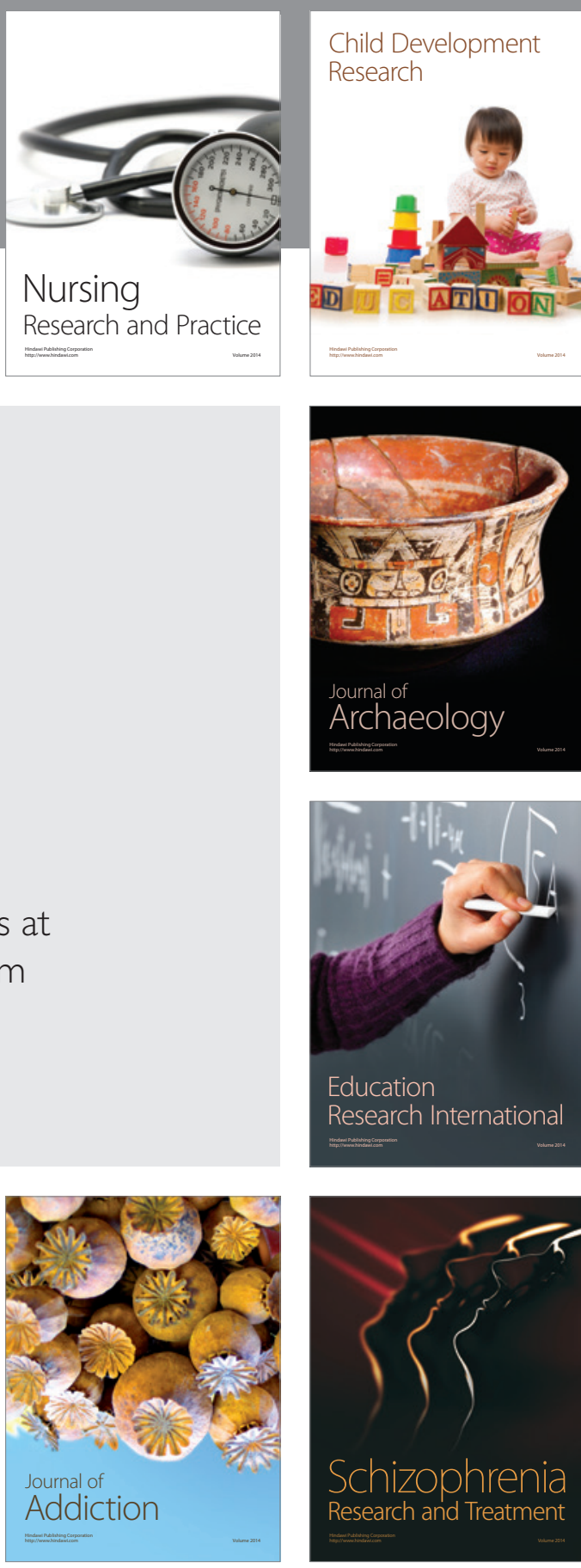

(D)
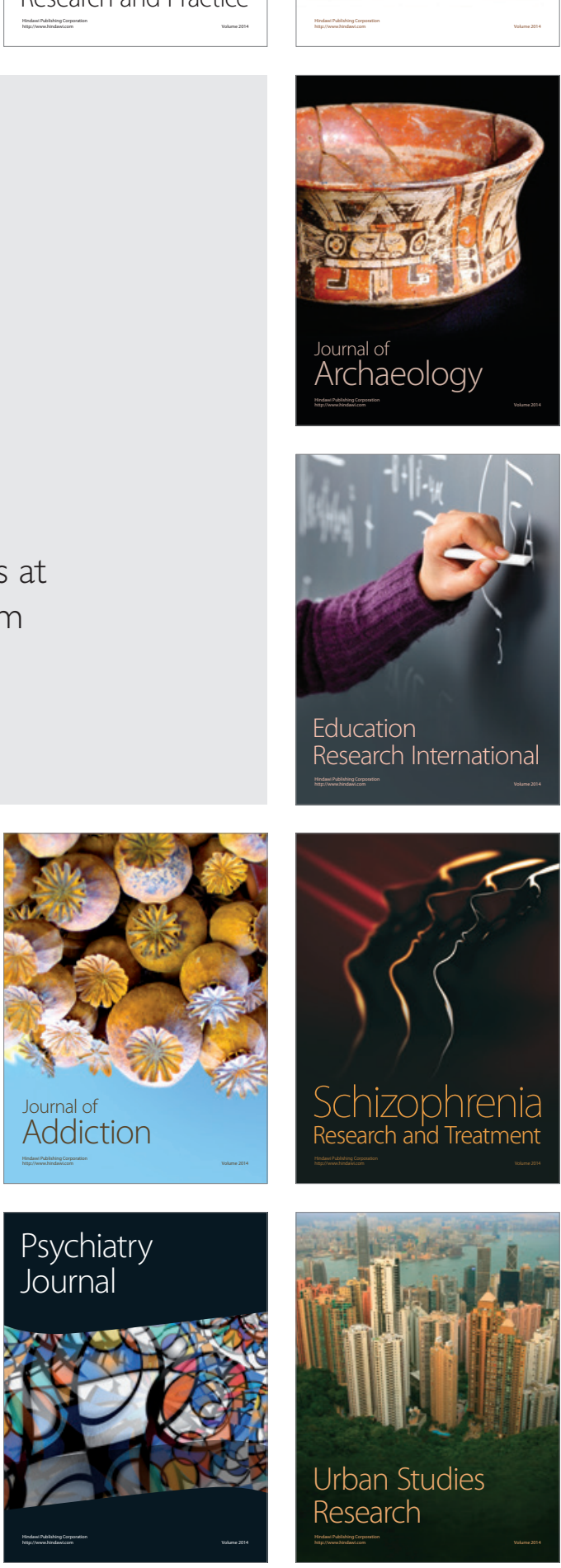